\title{
Patient utilization survey of mirabegron prescribed for overactive bladder
}

\author{
Päivi Rahkola-Soisalo ${ }^{1}$, Marcin Balcerzak ${ }^{2}$, Jarno Ruotsalainen ${ }^{2}$, Tomi S. Mikkola ${ }^{1,3}$ \\ ${ }^{1}$ Department of Obstetrics and Gynecology, University of Helsinki and Helsinki University Hospital, Helsinki, ${ }^{2}$ Farenta Oy, Espoo, ${ }^{3}$ Folkhälsan Research Center, Helsinki, \\ Finland
}

Purpose: Mirabegron, a $\beta_{3}$-adrenoreceptor agonist, is used to treat overactive bladder. The factors affecting persistence of mirabegron use or symptom improvement are not thoroughly known, but could be related to patient characteristics. Therefore, we evaluated persistence of medication use, symptom improvement, and quality of life among Finnish mirabegron users. In addition, we assessed possible predictors of change in these variables.

Materials and Methods: Participants (52 men, 118 women) with an initial mirabegron prescription were recruited nationwide from 79 pharmacies. Volunteers were interviewed at baseline and after 6 months. Subject and clinical characteristics, symptom severity, and quality of life (EQ-5D-5L) were assessed using a visual analogue scale.

Results: Of 170 participants, 144 (84.7\%) were reached after 6 months. The rate of persistent mirabegron use was 50.7\%. Experiencing adverse effects (29.6\%) was the most common reason for discontinuation of medication. A primary health care unit as a prescription site (odds ratio [OR], 2.3; 95\% confidence interval [CI], 1.03-4.9) was associated with increased risk for discontinuation. Mirabegron relieved symptoms in $45.2 \%$ and enhanced quality of life in $41.7 \%$ of the participants. Age $<64$ years was associated with better probability of symptom improvement $(\mathrm{OR}, 2.7 ; 95 \% \mathrm{Cl}, 1.1-6.8)$, whereas none of the other parameters assessed predicted change in quality of life.

Conclusions: In this Finnish population, 50.7\% of the participants continued using mirabegron after 6 months. The prescription site seemed to be important for persistent use, which may be related to patient counseling. Younger patients were more likely to benefit from treatment with mirabegron.

Keywords: Medication adherence; Quality of life; Urinary bladder; Urinary incontinence, urge

This is an Open Access article distributed under the terms of the Creative Commons Attribution Non-Commercial License (http://creativecommons.org/licenses/by-nc/4.0) which permits unrestricted non-commercial use, distribution, and reproduction in any medium, provided the original work is properly cited.

\section{INTRODUCTION}

An overactive bladder $(\mathrm{OAB})$ with or without urgency incontinence is a chronic disorder in both women and men [1]. Prevalence increases with age but varies among studies [2]. In Finland, over half of both women and men report any $\mathrm{OAB}$, whereas women are more likely to have wet $\mathrm{OAB}[3]$ than are men $(25.7 \%$ vs. $10.7 \%-18.3 \%$, respectively) [3,4]. An OAB decreases quality of life [3] and is associated with several comorbidities. Patients with $\mathrm{OAB}$ have increased risks for falls and fractures, urinary tract infections, depression, anxiety, and even mortality [5].

Received: 16 November, 2018 - Accepted: 21 January, 2019

Corresponding Author: Päivi Rahkola-Soisalo

Department of Obstetrics and Gynecology, Helsinki University Hospital, Haartmaninkatu 2, PO Box 140, FIN-00029 HUS, Helsinki, Finland TEL: +358-09-47111, FAX: +358-09-454-4104, E-mail: paivi.rahkola-soisalo@hus.fi

ORCID: https://orcid.org/0000-0001-7512-4823 
Known predisposing risk factors for $\mathrm{OAB}$ are diabetes and obesity [5], whereas recent findings indicate that migraine, fibromyalgia, chronic pelvic pain, dysmenorrhea, and allergic disorders are more common in women with $\mathrm{OAB}$ [6].

Nonmedical therapies for $\mathrm{OAB}$ include lifestyle adjustments with restricted fluid intake and bladder and pelvic floor training [7]. Previously, antimuscarinics were used as a first-line drug therapy for $\mathrm{OAB}$, but currently the $\beta_{3}$ adrenoreceptor agonist mirabegron is also widely used. Antimuscarinics and mirabegron have similar efficacy, but the typical antimuscarinic side effects with mirabegron, like dry mouth and constipation, are comparable to those for placebo [8,9]. However, better tolerance with mirabegron is not necessarily associated with better rates of persistent medication use [10,11]. The reasons affecting drug persistence are not known, but they are likely multifactorial. In addition to adverse effects, understanding the chronic state of $\mathrm{OAB}$ is important to prevent unrealistic expectations for drug efficacy [7,12]. Owing to the high prevalence and socioeconomic burden of $\mathrm{OAB}$ [2], more information on patient characteristics and factors affecting drug discontinuation is needed. We therefore conducted a survey to assess subject characteristics, quality of life, and drug use patterns in mirabegron-naïve patients and to evaluate possible factors predicting symptom improvement and/or therapy discontinuation.

\section{MATERIALS AND METHODS}

This was a noninterventional, longitudinal, medicine utilization survey conducted at 79 community pharmacies belonging to the pharmacy practice-based research network Farenta Research between June 2015 and March 2016. Participating pharmacies covered 17 of the 20 Finnish hospital district areas. Customers eligible for participation had to be $\geq 18$ years old and starting treatment with mirabegron for the first time. Patients giving consent to be further contacted were followed for 6 months.

The survey was conducted in accordance with the recommendations made by the Finnish National Advisory Board on Research Ethics [13]. All patients invited to participate provided informed consent and were given written information about the purpose of the survey as well as contact details for additional information. This was a survey and thus, the Ethichs Committee of the Helsinki University Hospital decided that a perimission was not needed. Therefore, the survey was conducted in accordance with the recommendations made by the Finnish National Advisory Board on Research Ethichs, as stated. At the pharmacy, the participants answered questions using a tablet (iPad; Apple Inc.). If the participant could not use the tablet independently, the pharmacist could assist or ask the questions as an interview and then type in the answers.

The questions created for the survey (in two language versions: Finnish and Swedish) included questions about subject characteristics (age, gender, height, and weight), health status (concomitant diseases, health-related quality of life), and disease characteristics (previous bladder- or prostate-related problems, previous surgery, deliveries, and severity of bladder symptoms) evaluated using the patient perception bladder condition (PPBC) scale and treatment profile (previous and concomitant medication).

A computer-assisted telephone interview was done 6 months after baseline with all participants who had given consent to be contacted further. The interviewers made at least four separate attempts to contact the patient via phone or text message. The telephone calls were all performed by trained, licensed pharmacists. A letter with information about the upcoming telephone interview containing the EQ5D-5L questionnaire [14] and the visual analogue scale (VAS) was sent to the participants before the interview. This was done to facilitate the interview by allowing the respondents to read the questions and response options thoroughly. All collected data were entered directly into the secure electronic database.

Descriptive analysis was carried out. Continuous variables were expressed with standard statistical measures: i.e., the number of observations, mean and/or median, and standard deviation (SD) for key variables. In addition, to find predictors of persistence in treatment, adjusted multivariate logistic regression models were used. The analyses were carried out by using IBM SPSS Statistics ver. 23.0 (IBM Co, Armonk, NY, USA).

\section{RESULTS}

In total, 118 women and 52 men met the inclusion criteria. The mean $( \pm \mathrm{SD})$ age of the participants was $69.7 \pm 11.6$ years, and 46 participants (27.1\%) were under 64 years of age. The majority (88.2\%) reported use of various concomitant medications (mean, 4.6; range, 1-17), of which hypercholesterolemia medication was the most common $(\mathrm{n}=58,34.1 \%)$ (Table 1). Previous anticholinergic medication use during the last 2 years was reported by 60 participants (35.3\%), and 10 (5.9\%) were using them at the time of the study. A primary health care unit was the most common prescription site $(\mathrm{n}=69,40.6 \%)$.

After 6 months, 104 women and 40 men were reached 
Table 1. Baseline clinical characteristics of study population

\begin{tabular}{|c|c|c|c|}
\hline Characteristic & All $(n=170)$ & Women $(n=118)$ & Men $(n=52)$ \\
\hline Age $(y)$ & $69.7 \pm 11.6(22-91)$ & $70.0 \pm 11.8(24-91)$ & $69.0 \pm 11.3(22-86)$ \\
\hline Body mass index $\left(\mathrm{kg} / \mathrm{m}^{2}\right)$ & $28.0 \pm 6.1(15.6-53.5)$ & $28.5 \pm 6.3(16.7-53.5)$ & $26.7 \pm 5.6(15.6-47.9)$ \\
\hline Retired & $131(77.1)$ & $95(80.5)$ & $36(69.2)$ \\
\hline At least one delivery & & $100(84.7)$ & \\
\hline Use of vaginal hormonal therapy & & $45(38.1)$ & \\
\hline Use of anti-cholinergic medication & $17(10.0)$ & $5(4.2)$ & $12(23.1)$ \\
\hline Use of a-adrenergic medication & & & $20(38.5)$ \\
\hline Any previous pelvic operation/procedure & $40(23.5)$ & $28(23.7)$ & $12(23.1)$ \\
\hline Tension-free tape operation & & $11(9.3)$ & \\
\hline Prolapse operation & & $7(5.9)$ & \\
\hline Botox-injection & & $1(0.8)$ & \\
\hline \multicolumn{4}{|l|}{ Lower urinary tract problem } \\
\hline Only bladder problems & & & $18(34.6)$ \\
\hline Only prostate problems & & & $8(15.4)$ \\
\hline Both & & & $23(44.2)$ \\
\hline \multicolumn{4}{|l|}{ Comorbidities } \\
\hline Hypercholesterolemia & $58(34.1)$ & $48(40.7)$ & $10(19.2)$ \\
\hline Diabetes & $38(22.4)$ & $28(23.7)$ & $10(19.2)$ \\
\hline Coronary heart disease & $23(13.5)$ & $16(13.6)$ & $7(13.5)$ \\
\hline Stroke & $7(4.1)$ & $3(2.5)$ & $4(7.7)$ \\
\hline Multiple sclerosis & $4(2.4)$ & $4(3.4)$ & \\
\hline Parkinson disease & $1(0.6)$ & $1(0.8)$ & \\
\hline \multicolumn{4}{|l|}{ Disease characteristics } \\
\hline Use of pads & $73(42.9)$ & $63(53.4)$ & $10(19.2)$ \\
\hline Previous use of anticholinergic medication & $60(35.3)$ & $43(36.4)$ & $17(32.7)$ \\
\hline Current use of anticholinergic medication & $10(5.9)$ & $4(3.4)$ & $6(11.5)$ \\
\hline \multicolumn{4}{|l|}{ Primary prescription site } \\
\hline Primary health care unit & $69(40.6)$ & $52(44.1)$ & $17(32.7)$ \\
\hline Secondary health care unit (hospital outpatient department) & $57(33.5)$ & $32(27.1)$ & $25(48.1)$ \\
\hline Private practitioner/occupational health care/other & $44(25.9)$ & $34(28.8)$ & $10(19.2)$ \\
\hline
\end{tabular}

Values are presented as mean \pm standard deviation (range) or number (\%).

for follow-up; thus, the complete study population consisted of 144 participants. Baseline symptom severity of these participants was not statistically different from those who were not followed up. Of the participants, 73 (50.7\%) were still using mirabegron. The most common reason for discontinuation was some adverse effect, including lack of efficacy ( $n=21,29.6 \%$ ). Other reasons were as follows: treatment did not reach expectations $(n=19,26.8 \%)$, no need for further medication ( $\mathrm{n}=6,8.5 \%)$, use of drug was not started $(\mathrm{n}=6,8.5 \%)$, doctor had recommended discontinuation $(n=5,7.0 \%)$, another medication was started $(n=3,4.2 \%)$, new diagnosis $(n=3,4.2 \%)$, prescription had ended without renewal $(n=2,2.8 \%)$, drug was too expensive $(n=1,1.4 \%)$, or some other reason $(n=5,7.0 \%)$. Prescription at the primary health care unit (odds ratio [OR], 23; 95\% confidence interval [CI], 1.03-4.9; $\mathrm{p}=0.04)$ and normal cholesterol levels (OR, 2.9; 95\% CI, 13-6.5; $\mathrm{p}=0.009$ ) were associated with increased risk for discontinuation (Table 2).

At baseline, the mean self-estimated symptom severity measured by PPBC was $3.8 \pm 0.9 \mathrm{SD}$, and that after 6 months was 3.4 \pm 1.2 SD $(p<0.001)$ (Table 3). After 6 months of followup, 65 participants (45.1\%) showed improvement, 53 (36.8\%) had no change, and 26 (18.1\%) showed worsening. An age of less than 64 years increased the possibility for symptom improvement (OR, 2.7; 95\% CI, 1.1-6.8; $p=0.04$ ) (Table 4).

Changes in quality of life between baseline and followup were not detected in EQ-5D-5L (mean, 0.87 vs. 0.84, not significant [NS]) or VAS (mean, 67.7 vs. 69.7, NS) scores. After 6 months, 41 (28.5\%) participants showed improvement, 22 (15.3\%) showed no change, and 81 (56.3\%) reported decreased quality of life by the EQ-5D-5L. Quality of life evaluated by the VAS improved in 60 participants (41.7\%) and decreased in $53(36.8 \%)$ during observation. None of the tested variables predicted improvement in the EQ-5D-5L score. 
Table 2. ORs and $95 \% \mathrm{Cl}$ for discontinuation of mirabegron

\begin{tabular}{llcc}
\hline & OR & 95\% Cl & p-value \\
\hline Normal weight & 2.1 & $0.9-4.5$ & 0.08 \\
Prescription at primary health care unit & 2.3 & $1.03-4.9$ & 0.04 \\
Age under 64 years & 1.5 & $0.7-3.2$ & 0.3 \\
Normal cholesterol levels & 2.9 & $1.3-6.5$ & 0.009 \\
Previous pelvic floor operation & 2.2 & $0.9-5.3$ & 0.07 \\
No previous antimuscarinic medication & 1.2 & $0.5-2.5$ & 0.7 \\
Minor baseline symptoms & 1.4 & $0.6-3.0$ & 0.5 \\
\hline
\end{tabular}

$\mathrm{OR}$, odds ratio; $\mathrm{Cl}$, confidence interval.

Table 3. Self-evaluated symptom severity (from 1 to 6 ) at the baseline and after 6 months of follow-up

\begin{tabular}{lcccccc}
\hline & No problem & $\begin{array}{c}\text { Very minor } \\
\text { problem }\end{array}$ & $\begin{array}{c}\text { Some minor } \\
\text { problem }\end{array}$ & $\begin{array}{c}\text { Moderate } \\
\text { problem }\end{array}$ & $\begin{array}{c}\text { Severe } \\
\text { problem }\end{array}$ & $\begin{array}{c}\text { Extremely } \\
\text { severe problem }\end{array}$ \\
\hline All baseline responders $(n=170)$ & $3(1.8)$ & $11(6.5)$ & $35(20.6)$ & $95(55.9)$ & $19(11.2)$ & $7(4.1)$ \\
6 months of follow-up $(n=144)$ & $14(9.7)$ & $12(8.3)$ & $50(34.7)$ & $47(32.6)$ & $17(11.8)$ & $4(2.8)$ \\
\hline
\end{tabular}

Values are presented as number (\%).

Table 4. ORs and 95\% Cl for symptom improvement after 6 months use of mirabegron

\begin{tabular}{llll}
\hline & OR & 95\% Cl & p-value \\
\hline Female & 1.5 & $0.6-4.2$ & 0.4 \\
Prescription at private doctor & 2.3 & $0.8-7.0$ & 0.1 \\
Age under 64 years & 2.7 & $1.1-6.8$ & 0.04 \\
Nondiabetic & 1.0 & $0.3-2.7$ & 1.0 \\
No daily use of pads & 1.8 & $0.8-4.5$ & 0.2 \\
No previous antimuscarinic medication & 1.3 & $0.5-3.3$ & 0.6 \\
Continuation of mirabergon use & 1.0 & $0.4-2.3$ & 1.0 \\
\hline
\end{tabular}

$\mathrm{OR}$, odds ratio; $\mathrm{Cl}$, confidence interval.

\section{DISCUSSION}

In this prospective survey representing clinical practice in Finland, half of the participants had continued using mirabegron after 6 months. Symptom control improved in $45 \%$ of patients at the 6 -month follow-up.

The most common reasons for discontinuing mirabegron were adverse effects (including lack of efficacy) and unmet expectations. These reasons were also well recognized in previous studies [12,15], whereas in a randomized controlled trial, adverse events led to discontinuation in only $6.4 \%$ of patients during 12 months of use [8]. It has been speculated that medication is better tolerated in a trial setting than in clinical practice owing to stricter inclusion criteria, better information provided to patients, and regular follow-up. This is also supported by our findings indicating the importance of the type of site where the prescription was issued. It is likely that prescribers in secondary health care units informed patients more thoroughly about the efficacy and necessity of long-term use of the medication. Moreover, it is possible that patients from secondary prescription sites were selected and the diagnoses were more accurate.

Comparison of rates of discontinuation of medication between different $\mathrm{OAB}$ medication studies is challenging owing to large heterogeneity in inclusion and exclusion criteria and follow-up times. Retrospective studies of $\mathrm{OAB}$ medication use including both genders, including naïve and long-term users, found persistence rates of $31.7 \%$ [10] and 34\% [16] after 12 months. In a prospective nonrandomized study of mirabegron-naïve women only, $25 \%$ had continued to use the medication after 1 year [12], whereas in a retrospective study comprising both men and women with both naïve and long-term users, $48 \%$ had continued use after 6 months [15]. The lowest persistence rate (12.2\%) after 12 months was found in a randomized trial comparing treatment-naïve mirabegron and solifenacin users [17]. In most of these studies, the participants were younger than those in our study. This could explain at least in part why we could not confirm the previous finding that young age is associated with an increased rate of discontinuation [10]. Instead, 
we found that using hypercholesterolemia treatment increased the possibility of continuing mirabegron use over 6 months. A possible explanation for this could be the known association between $\mathrm{OAB}$ and metabolic syndrome [18]. Another possibility is that participants receiving hypercholesterolemia treatment were accustomed to regular medication and thus persisted more of ten than did patients without chronic treatment. This is supported by the finding that concomitant medication decreases the risk for discontinuation [10]. However, owing to our study setup, these data are not robust and need to be interpreted with caution.

The rate of those who reported benefit from mirabegron treatment was $45 \%$. Because this rate is close to the rate of persistence, it is likely that those who benefited also continued with the treatment. This rate was close to the previously reported rate of $39 \%$ after 6 months [15], whereas another study reported an $85 \%$ satisfaction rate at 12 months of mirabegron use [12]. However, these numbers are not fully comparable, because they are based on different question patterns, as well as different rates of discontinuation and dropout. Moreover, it is likely that etiologic factors determine medication response; thus, some subpopulations might benefit more than others. Identification of these subpopulations and associated factors would be essential for clinical practice. Our data indicated that younger $(<64$ years of age) participants received more benefit from the therapy. This may be because age is an independent risk factor for $\mathrm{OAB}$ [19], but it is also possible that $\mathrm{OAB}$ in the elderly is more often multifactorial, resulting in diminished relief of symptoms.

Six months of mirabegron medication did not improve overall quality of life. A 12-week study comparing mirabegron and tolterodine showed enhanced quality of life assessed by the same questionnaire [20]; however, the followup time was shorter, and it is possible that the trial setup differed from clinical practice. Moreover, most of our study population had some comorbidity being treated with other medications, which may also have diluted the benefit of mirabegron.

We readily admit that our study had several limitations. First, it was not technically possible to record those who declined participation, which may at least in part explain the relatively high mean age of our participants. On the other hand, it is possible that elderly patients are treated with mirabegron rather than with antimuscarinics owing to anticholinergic side effects. Second, we were not able to verify and confirm the diagnosis of $\mathrm{OAB}$ by voiding diaries or urodynamic parameters at the pharmacy setting. Third, the study population was heterogeneous with a rather low number of participants, which limited subgroup comparisons. On the other hand, the survey technique could be regarded as a strength of our study. This method made it possible to enroll patients from both primary and secondary health care units. Moreover, participating pharmacies covered the most regions, and thus, these survey results are representative of the whole country. Finally, a prospective study setting with a rather low dropout rate (15.3\%) can also be considered as a strength.

\section{CONCLUSIONS}

We found that in our nationwide study, 50.7\% continued using mirabegron after 6 months of follow-up. A primary health care unit as a prescription site was associated with risk of discontinuation, whereas those under 64 years of age were more likely to benefit from mirabegron. Our findings highlight the importance of patient counseling and also warrant further studies of risk factors for both discontinuation and symptom improvement in a larger population to identify those who might benefit most from mirabegron treatment.

\section{CONFLICTS OF INTEREST}

The authors have nothing to disclose.

\section{ACKNOWLEDGMENTS}

This survey was sponsored by Astellas Pharma A/S, Kajakvej 2 DK-2770 Kastrup, Denmark. MB and JR are employees of Farenta $\mathrm{Oy}$.

PR-S has received funding for congress trips from Johnson \& Johnson and Astellas Pharma. TM has been a speaker and/or received consulting fees from Mylan and Novo Nordisk.

\section{REFERENCES}

1. Abrams P, Artibani W, Cardozo L, Dmochowski R, van Kerrebroeck P, Sand P; International Continence Society. Reviewing the ICS 2002 terminology report: the ongoing debate. Neurourol Urodyn 2009;28:287.

2. Milsom I, Coyne KS, Nicholson S, Kvasz M, Chen CI, Wein AJ. Global prevalence and economic burden of urgency urinary incontinence: a systematic review. Eur Urol 2014;65:79-95.

3. Vaughan CP, Johnson TM 2nd, Ala-Lipasti MA, Cartwright R, Tammela TL, Taari K, et al. The prevalence of clinically mean- 
ingful overactive bladder: bother and quality of life results from the population-based FINNO study. Eur Urol 2011;59:629-36.

4. Pöyhönen A, Häkkinen JT, Koskimäki J, Hakama M, Tammela TL, Auvinen A. Empirical evaluation of grouping of lower urinary tract symptoms: principal component analysis of Tampere Ageing Male Urological Study data. BJU Int 2013;111:467-73.

5. Coyne KS, Wein A, Nicholson S, Kvasz M, Chen CI, Milsom I. Comorbidities and personal burden of urgency urinary incontinence: a systematic review. Int J Clin Pract 2013;67:1015-33.

6. Altman D, Iliadou AN, Lundholm C, Milsom I, Pedersen NL. Somatic comorbidity in women with overactive bladder syndrome. J Urol 2016;196:473-7.

7. Blasco P, Valdivia MI, Oña MR, Roset M, Mora AM, Hernández M. Clinical characteristics, beliefs, and coping strategies among older patients with overactive bladder. Neurourol Urodyn 2017;36:774-9.

8. Chapple CR, Kaplan SA, Mitcheson D, Blauwet MB, Huang $\mathrm{M}$, Siddiqui E, et al. Mirabegron $50 \mathrm{mg}$ once-daily for the treatment of symptoms of overactive bladder: an overview of efficacy and tolerability over 12 weeks and 1 year. Int J Urol 2014;21:960-7.

9. Rossanese M, Novara G, Challacombe B, Iannetti A, Dasgupta P, Ficarra V. Critical analysis of phase II and III randomised control trials (RCTs) evaluating efficacy and tolerability of a $\beta_{3}$-adrenoceptor agonist (Mirabegron) for overactive bladder (OAB). BJU Int 2015;115:32-40.

10. Wagg A, Franks B, Ramos B, Berner T. Persistence and adherence with the new beta- 3 receptor agonist, mirabegron, versus antimuscarinics in overactive bladder: early experience in Canada. Can Urol Assoc J 2015;9:343-50.

11. Kim TH, Lee KS. Persistence and compliance with medication management in the treatment of overactive bladder. Investig Clin Urol 2016;57:84-93.

12. Duckett J, Balachandran A. Tolerability and persistence in a large, prospective case series of women prescribed mirabegron. Int Urogynecol J 2016;27:1163-7.

13. National Advisory Board on Research Ethics in Finland. Ethical principles of research in the humanities and social and behavioural sciences and proposals for ethical review [Internet]. Helsinki: National Advisory Board on Research Ethics in Finland; 2009. Available from: http://www.tenk.fi/sites/tenk.fi/ files/ethicalprinciples.pdf.

14. EuroQol Group. EuroQol--a new facility for the measurement of health-related quality of life. Health Policy 1990;16:199-208.

15. Pindoria N, Malde S, Nowers J, Taylor C, Kelleher C, Sahai A. Persistence with mirabegron therapy for overactive bladder: a real life experience. Neurourol Urodyn 2017;36:404-8.

16. Chapple CR, Nazir J, Hakimi Z, Bowditch S, Fatoye F, Guelfucci F, et al. Persistence and adherence with mirabegron versus antimuscarinic agents in patients with overactive bladder: a retrospective observational study in UK clinical practice. Eur Urol 2017;72:389-99.

17. Kinjo M, Sekiguchi Y, Yoshimura Y, Nutahara K. Long-term persistence with mirabegron versus solifenacin in women with overactive bladder: prospective, randomized trial. Low Urin Tract Symptoms 2018;10:148-52.

18. Bunn F, Kirby M, Pinkney E, Cardozo L, Chapple C, Chester $\mathrm{K}$, et al. Is there a link between overactive bladder and the metabolic syndrome in women? A systematic review of observational studies. Int J Clin Pract 2015;69:199-217.

19. de Ridder D, Roumeguère T, Kaufman L. Overactive bladder symptoms, stress urinary incontinence and associated bother in women aged 40 and above; a Belgian epidemiological survey. Int J Clin Pract 2013;67:198-204.

20. Pavesi M, Devlin N, Hakimi Z, Nazir J, Herdman M, Hoyle C, et al. Understanding the effects on HR-QoL of treatment for overactive bladder: a detailed analysis of EQ-5D clinical trial data for mirabegron. J Med Econ 2013;16:866-76. 